\title{
Multilateralismo, Democracia e Política Externa no Brasil: Contenciosos das Patentes e do Algodão na Organização Mundial
} Marcelo Fernandes de Oliveira**

\section{Introdução}

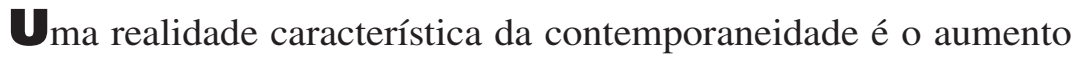
sem precedentes da interação entre as políticas domésticas e o contexto internacional. As questões internacionais têm produzido, crescentemente, custos e benefícios assimétricos para as sociedades e vice-versa, o que tem conduzido, em muitas ocasiões, à mobilização dos atores domésticos, sobretudo daqueles negativamente afetados, na defesa dos seus interesses durante a negociação de acordos co-

\footnotetext{
*Agradeço Thiago Lima pela elaboração do material empírico relativo ao contencioso do algodão. Artigo recebido em fevereiro de 2005 e aceito para publicação em maio de 2006.

***Doutor em Ciência Política na Universidade de São Paulo (USP), professor de Relações Internacionais da Universidade Estadual Paulista (Unesp) e pesquisador do Centro de Estudos de Cultura Contemporânea (Cedec), do Núcleo de Pesquisa de Relações Internacionais (Nupri/USP) e do Instituto de Estudos Econômicos e Internacionais.
} 
merciais. E deslocado para a esfera pública a discussão da política externa que no Brasil foi considerada prerrogativa do Poder Executivo e de sua burocracia especializada (SOARES DE LIMA, 2000).

O Ministério das Relações Exteriores (MRE) é o responsável pela formulação de política externa e pelas negociações internacionais do país. Historicamente, o MRE manteve-se distante da sociedade, concentrando as decisões que representariam o interesse nacional dentro de seu corpo burocrático. O MRE relaciona-se com outros ministérios e com a Presidência da República, mas a interação com a sociedade e seus grupos de interesse é bastante baixa. É nesse sentido que se diz que o MRE sofre de insulamento burocrático.

Recentemente, na segunda metade da década de 1990, o MRE passou a intensificar suas relações com a sociedade, promovendo consultas e seminários com empresários, intelectuais, associações de classe e demais grupos de interesse nas questões internacionais do país. Contudo, esses grupos participam apenas de forma opinativa, não regular e sem participação direta no processo de formulação da política exterior a ser adotada nos foros de negociações. Assim, as pressões para o posicionamento do MRE no cenário internacional ocorrem de modo informal e não institucionalizado. Podem-se privilegiar alguns grupos e mesmo vetar certos interesses por motivos ideológicos que, não necessariamente, representariam a sociedade brasileira.

O fato é que, com o adensamento da globalização, os âmbitos doméstico e internacional estão cada vez mais interdependentes e é necessário que as estruturas governamentais estejam aptas para lidar com essa relação. Surge a necessidade de uma interligação virtuosa entre os policy-makers, o Poder Legislativo e os atores da sociedade civil, em busca da maximização de possíveis oportunidades para satisfazer as necessidades do país. Ou seja, estabelecer canais de comunicação abertos e institucionalizados entre os formuladores e os atores do- 
Multilateralismo, Democracia e Política

Externa no Brasil...

mésticos à procura de sintonia para a defesa dos interesses brasileiros no mundo.

Essa maior interação teria alguns riscos. Por um lado, projetos de longo prazo poderiam ser prejudicados por questões conjunturais e eleitorais. Mas mesmo o insulamento burocrático, tradicionalmente considerado como fundamental para a boa condução da política externa no passado, não pode evitar a apropriação do Estado pelos grupos de interesses mais poderosos. Nem de tornar a sociedade refém do "ditador benevolente" que, supostamente, conhece os interesses nacionais no sistema internacional. Por outro lado, o relacionamento mais próximo entre sociedade e policy-makers produziria um mapeamento mais acurado dos interesses e capacidades nacionais que o MRE deveria representar na sociedade internacional. Paralelamente, a transparência do processo poderia inibir desvios egoístas.

Desse modo, parece que a questão a ser equacionada é a seguinte: qual o melhor meio de se elaborar a política externa brasileira na atualidade? O democrático? Ou o insulamento burocrático?

Em minha opinião, nem um nem outro contexto em suas formas puras, mas sim um modelo a ser construído que estabeleça novos padrões de relacionamentos entre as estruturas burocráticas do Estado, o Poder Legislativo e grupos de interesse empresariais, intelectuais, sociais etc. Seria necessário o aprofundamento e a criação de novas instituições domésticas democráticas, além das já existentes, tais como fóruns de debates, com participação aberta aos atores nacionais interessados em questões internacionais. $\mathrm{O}$ intuito seria promover a interação virtuosa entre policy-makers, legisladores e grupos de interesses, imprimindo elevado grau de transparência ao processo de formulação de política externa, sem romper com a prerrogativa do Poder Executivo na condução das relações internacionais do Estado via MRE. 
Em outras palavras, manter-se-ia a capacidade do Poder Executivo em determinar a agenda e desenvolver negociações, mas com o devido debate com a sociedade e com o Legislativo. Reconheço que questões ligadas à segurança merecem tratamento mais sigiloso. Porém, as questões comerciais e de cooperação técnica, que ocupam maior espaço na agenda de política externa brasileira, deveriam ser tratadas de forma institucionalizada e que garantisse que os interesses da sociedade não fossem colocados apenas de forma opinativa.

Nesse sentido, faz-se necessária a elaboração de mecanismos e instrumentos por parte do Poder Legislativo que tenha como função retomar seu papel, de freios e contrapesos ao Executivo, desde que devidamente assessorado por grupos especializados e capazes de elucidar as questões internacionais em jogo. Paralelamente, o MRE deveria contar com mecanismos para absorver as demandas de grupos de interesses domésticos. O Projeto de Lei 189/03 ${ }^{1}$ do senador Eduardo Suplicy (PT/SP), que tem como proposta criar uma Trade Promotion Authority (TPA) à brasileira, como a existente nos Estados Unidos, poderia criar essas condições e as atividades da Coalizão Empresarial Brasileira (CEB) durante a permanência de Celso Lafer (2001-2003), como ministro do MRE durante o segundo governo Fernando Henrique Cardoso (FHC), poderia servir como ponto de partida em busca de aperfeiçoamentos.

Ainda que não tenhamos um desenho institucional altamente desenvolvido, acredito que esse debate interessa, e muito, à sociedade brasileira. Acredito também que o tema deve ser levado adiante e disseminado em universidades, centros de pesquisa, associações de classe, representações de interesses privados, governos, enfim, para todos aqueles interessados nos impactos que questões internacionais podem ter domesticamente.

Nesta direção, buscarei compreender neste artigo os desdobramentos dessa dinâmica por meio da problematização da temática do mul- 
Multilateralismo, Democracia e Política Externa no Brasil...

tilateralismo, da democracia e do processo de formulação da política externa do Brasil a partir de duas experiências concretas na OMC: 1) o contencioso entre Estados Unidos e Brasil em torno das patentes dos medicamentos para o tratamento de HIV e 2) o contencioso do algodão contra subsídios agrícolas.

A partir dessas duas análises empíricas, sugerirei que uma maior abertura e uma maior institucionalização do relacionamento entre policy-makers e atores das organizações da sociedade civil podem possibilitar um melhor atendimento às demandas da sociedade brasileira, melhorando a qualidade técnica da negociação e contribuindo para a democratização da construção do interesse nacional a ser defendido no exterior pela diplomacia brasileira. Gerando ainda maior credibilidade e legitimidade internacional para as ações do país no exterior, na medida em que essa nova dinâmica pode também servir para o aperfeiçoamento das instituições democráticas brasileiras no tocante à política externa.

Além disso, as duas experiências são ilustrativas para nos indicar padrões de relacionamento entre policy-makers e sociedade civil e, a partir deles, podermos refletir sobre como iniciar a elaboração de instituições democráticas para a formulação da política externa que potencializem os interesses brasileiros com maior credibilidade e legitimidade no mundo.

Para tanto, na próxima seção discutirei como o multilateralismo foi eleito opção estratégica da política externa do Brasil durante os anos 1990, especificamente a partir da era FHC que elegeu a OMC como o foro de excelência para a defesa dos interesses nacionais brasileiros. Nas duas seções seguintes, analisarei a concretização dessa premissa em torno dos contenciosos das patentes farmacêuticas e da questão dos subsídios agrícolas, especificamente o caso do algodão contra os Estados Unidos. Por fim, nas considerações finais, buscarei avaliar a opção brasileira do ponto de vista doméstico e internacional. 


\section{O Multilateralismo como Opção Estratégica do Brasil}

A diplomacia brasileira alcançou legitimidade internacional graças ao seu legado histórico-diplomático. Este sempre buscou engendrar consensos na agenda internacional em torno de uma atuação e inserção pautadas no pacifismo, no respeito ao direito internacional, na defesa dos princípios de autodeterminação e não-intervenção e, por fim, no pragmatismo como instrumentos necessários e eficazes para a legitimação dos interesses do país no mundo (OLIVEIRA, 2003).

Na época da Guerra Fria, na interpretação de Araújo Castro (1982), esse legado se traduziu em uma política decididamente resistente à consolidação de instituições e regimes, considerados engessadores da hierarquia de poder existente. Logo, o exercício da autonomia do Brasil deveria ocorrer pela distância. A execução dos interesses nacionais dependia de ampla margem de manobra vis-à-vis o meio internacional.

Durante os anos 1990, sobretudo na era FHC (1995-2002), operacionalizou-se uma radical reinterpretação desse legado. Passou a se considerar que a ação do Brasil no mundo deveria pautar-se por uma nova agenda internacional pró-ativa, determinada pela lógica da autonomia pela integração (VIGEVANI; OLIVEIRA, 2003, p. 32). "De acordo com essa perspectiva, o país deveria ampliar o poder de controle sobre o seu destino, sendo a resolução de seus problemas melhor viabilizada pela participação ativa na elaboração das normas e das pautas de conduta da ordem mundial" (FONSECA JR., 1998, p. 363).

Em outras palavras, houve uma guinada na interpretação do legado histórico-diplomático do Brasil. A base filosófica manteve-se. Entretanto, a prática alterou-se porque a participação ativa na organização e na regulamentação das relações internacionais, nas mais diversas áreas, passou a ser considerada como essencial para o estabe- 
Multilateralismo, Democracia e Política Externa no Brasil...

lecimento de um environment de convívio favorável à realização do principal objetivo do país, ou seja, garantir o seu desenvolvimento econômico.

A partir de então, a execução dos interesses nacionais dependia da capacidade do país em ajustá-los às tendências do mundo contemporâneo, da modernidade, em um entorno em que prevaleciam concepções liberais. Assim, o interesse nacional é o de captar as tendências profundas, buscando ajustar-se às dinâmicas da ordem mundial que podem ser úteis à legitimação e à concretização dos próprios objetivos. Segundo Cardoso (2006, p. 604-606):

"[A] política externa que persegui desde minha curta passagem pelo Itamaraty (de outubro de 1992 a maio de 1993) buscou 'a autonomia pela participação' numa realidade internacional cambiante, em contraposição à 'autonomia pela distância' da ordem mundial vigente, que em momentos anteriores marcou governos autoritários. [...] O Itamaraty, geralmente entregue a diplomatas de carreira naqueles anos de tendência tecnocrática, acabou por desenhar uma política de defesa de nossos interesses que jogava com o terceiro-mundismo. [...] A política externa do regime militar tinha a legitimidade do governo que a criara. Após a queda do muro de Berlim, em 1989, e com a aceleração dos processos econômicos vinculados à globalização, nos anos 1980 e 1990, havia que rever seus objetivos centrais".

Nesta perspectiva, Lafer (2000, p. 263) ensina que, na atualidade, essa política

“[...] se traduz em obter no eixo assimétrico das relações internacionais do Brasil um papel na elaboração e aplicação das normas e das pautas de conduta que regem os grandes problemas mundiais, que tradicionalmente as grandes potências buscam avocar e, na medida do possível, exercer com exclusividade".

No caso brasileiro, as questões de segurança foram consideradas menos importantes do que aquelas relacionadas à problemática do desenvolvimento econômico que, ao longo dos anos, tornou-se o foco central da ação internacional do país. Portanto, o país deveria participar da elaboração de bens públicos globais que lhe garantisse a opor- 
tunidade de galgar desenvolvimento econômico e solucionar seus problemas domésticos.

Logo, a defesa do multilateralismo encarnado pela OMC enquadra-se na mesma perspectiva de atuação propositiva, de elaboração de bens públicos globais, de aceitação do jogo, buscando dentro dele formas de legitimar suas próprias posições. É por isso que Lafer (2000, p. 265) sugere que o Brasil deve considerar a OMC

"[...] o melhor tabuleiro para gerar poder pela ação conjunta, permitindo ao país exercitar a sua competência na defesa dos interesses nacionais. É neste tipo de tabuleiro que reside o melhor do nosso potencial para atuar na elaboração das normas e pautas de conduta da gestão do espaço da globalização no campo econômico, no qual reside o nosso maior desafio".

É a partir dessa perspectiva, denominada por Fonseca Jr. (1998) de “autonomia pela integração", que nos anos 1990, principalmente na Era FHC, prevaleceu a política pela qual se considerou como melhor opção para os interesses do país atuar simultaneamente nos três tabuleiros das negociações comerciais multilaterais nas quais o país estava envolvido: OMC, Mercosul-União Européia e Área de Livre Comércio das Américas (ALCA). Contudo, houve uma clara opção no sentido de "dar prioridade às negociações multilaterais sobre as bilaterais, por considerar aquelas as que ofereciam maiores possibilidades de êxitos para uma nação com as características do Brasil" (SILVA, 2002, p. 325).

Portanto, dentre as negociações, as desenvolvidas no quadro da OMC foram consideradas "o foro por excelência, e o que melhor atende a nossos interesses, no que tange à formulação de regras de regulamentação, no plano internacional, das atividades econômicas" (LAFER, 2001, p. 56). Isso me permite afirmar que o uso do multilateralismo ensejado pela OMC por meio da construção de regras de conduta econômica global em consonância com os interesses nacionais se tornou uma das principais opções estratégicas do Brasil. 
Multilateralismo, Democracia e Política

Externa no Brasil...

Esta preferência se justifica porque a OMC

“[...] enseja coligações de geometria variável, em função da variedade dos temas tratados; por isso, no multilateralismo comercial não prevalecem 'alinhamentos automáticos'. Na OMC, na formação destas coligações, não só os Estados Unidos têm peso. [...] [Todos os países têm e] possuem poder de iniciativa pela força da ação conjunta e finalmente, a regra e a prática do consenso no processo decisório têm um componente de democratização que permeia a vida da organização" (LAFER, 1998, p. 14-15).

Por isso, um dos objetivos do Brasil é injetar vigor renovado na OMC (LAFER, 2002). Essas possibilidades não são automáticas, devem ser compreendidas, analisadas e canalizadas pelo Estado e pela sociedade brasileira em prol dos seus interesses. Isso exige esforço e recursos adequados em um contexto de duplo desafio: doméstico principalmente de formulação de política externa em contexto democrático - e internacional, aprofundamento de aspectos negativos da globalização. Buscarei demonstrar nas próximas seções, por meio do exame da questão de patentes e subsídios agrícolas, caminhos alternativos e factíveis para a consolidação dessa dinâmica virtuosa entre Estado e sociedade brasileira durante negociações internacionais que levaram ao alcance de resultados claramente satisfatórios.

Enfim, posso afirmar que a OMC foi considerada a melhor opção para os interesses brasileiros nas questões econômicas, já que "protegeria contra abusos e lhe ofereceria recursos adequados para a resolução razoavelmente justa de conflitos que, de outra forma, seriam resolvidos pela lei do mais forte" (SILVA, 2002, p. 325). Como veremos adiante, o principal recurso é o mecanismo de solução de controvérsias, utilizado pelo governo e pelas empresas nos contenciosos comerciais em que todos os procedimentos diplomáticos usuais foram utilizados de forma "vitoriosa" para os interesses do país.

Para finalizar, vale ressaltar a idéia de que a OMC é uma organização internacional nova. Nela, há a possibilidade de países menos poderosos prevalecerem sobre os mais poderosos em contenciosos interna- 
cionais. Inclusive em assuntos de importância crucial para países em desenvolvimento, como, por exemplo, a liberalização do comércio de bens agrícolas, como ilustrarei com o "triunfo" brasileiro contra os Estados Unidos na questão dos subsídios agrícolas do algodão. Além disso, pode abrir caminho para uma maior utilização dos mecanismos de solução de controvérsias da OMC por outros países, minando a argumentação jurídica e moral dos países desenvolvidos na prática de garantir subsídios aos seus produtos agrícolas, enquanto pressionam os menos desenvolvidos para assinarem acordos de proteção para patentes, que podem impedir a formulação de políticas públicas em prol do bem-estar de sociedades mais necessitadas.

É válido ressaltar que tudo isso pode ocorrer no bojo de alianças estratégicas de geometria variável possibilitadas pelas regras da OMC, mas que exigem, também, graus consideráveis de democratização fundamentais para a canalização do apoio da sociedade civil doméstica e internacional, os quais garantem legitimidade e credibilidade para a política externa brasileira.

\section{O Contencioso Brasil X EUA das Patentes nas Negociações da OMC}

A disputa acerca das patentes entre Brasil e Estados Unidos foi uma questão de grande relevância social e econômica. O governo brasileiro se opôs à indústria farmacêutica, sobretudo aos laboratórios estadunidenses, quando demandou o direito de override (passar por cima) da exclusividade de comercialização e/ou produção (market exclusivity) de medicamentos usados no tratamento de AIDS. Utilizando-se do argumento de que o bem-estar público deveria prevalecer sobre o lucro, o Brasil defendeu sua posição. A disputa teve início quando os Estados Unidos alegaram que o Brasil não estava respeitando o Acordo sobre Aspectos de Direitos de Propriedade Intelectual relacionados ao Comércio (em inglês, Agreement on Trade-Related 
Multilateralismo, Democracia e Política Externa no Brasil...

Aspects of Intellectual Property Rights (TRIPS)) por causa dos artigos 68 e 71 da Lei 9279/96, que previam a possibilidade do uso de licença compulsória em casos de emergência da saúde pública.

Em 2000, os Estados Unidos questionaram ambos os artigos, sugerindo que não estavam de acordo com o TRIPS. O Brasil foi inserido na Section 301 Watch List, acusado de ser "desrespeitador de patentes" (patent-miscreant). Em 30 de maio de 2000, os Estados Unidos entraram com pedido de consultas junto ao governo brasileiro na OMC. Não satisfeitos com a resposta brasileira, em 9 de janeiro de 2001, entraram com pedido de estabelecimento de panel no Órgão de Solução de Controvérsias da OMC, apresentando a mesma queixa e afirmando que as consultas não trouxeram os resultados esperados, tampouco a solução para o conflito.

Em junho de 2001, após diversas reuniões, negociações e consultas, os países chegaram a um acordo, que foi considerado como uma "vitória" brasileira. Os Estados Unidos admitiram a possibilidade de quebra de patentes em questões de saúde pública de países em desenvolvimento.

Por que o Brasil se sagrou vitorioso na OMC nesse contencioso das patentes contra os Estados Unidos?

O sucesso brasileiro deveu-se à combinação de diversos fatores. Em primeiro lugar, os negociadores do país na OMC utilizaram a premissa humanitária de que o bem público deve prevalecer sobre o lucro. Assim, legitimou a estratégia de defesa brasileira e obteve simpatia internacional da maioria dos outros países. Entre eles, África do Sul (país que sofre com epidemia de HIV/AIDS e, como o Brasil, não possui recursos financeiros para garantir tratamento gratuito adequado a todos que necessitam), Índia (país com tecnologia avançada na produção de genéricos e medicamentos em geral, ocupando papel importante no comércio internacional de medicamentos, interessado em vender genéricos), Quênia, Moçambique, Zimbábue, Ruanda e 
outros países em desenvolvimento (interessados em transferência de tecnologia e cooperação técnica internacional para o tratamento dos seus doentes de AIDS).

A opinião pública internacional e as comunidades epistêmicas ${ }^{2}$ (HAAS, 1992) também foram essenciais para a "vitória" porque defenderam o direito do Brasil e dos países em desenvolvimento ao acesso a medicamentos. Entre os atores principais estavam organizações não-governamentais (ONGs) como Médecins Sans Frontièrs, Health GAP, Oxfam e até mesmo o Programa Conjunto das Nações Unidas sobre HIV/AIDS (UNAIDS), a Organização Mundial da Saúde (OMS) etc., envolvidas com os temas de saúde pública e direitos humanos e até mesmo parcelas consideráveis da sociedade civil estadunidense. Essas comunidades estavam convencidas de que o Brasil deveria ter o direito de fornecer medicamentos à sua população a despeito da redução dos lucros da indústria farmacêutica.

O legado histórico-diplomático brasileiro, traduzido no conceito de "autonomia pela integração", foi fundamental para a obtenção de tanto apoio internacional, visto que a solicitação dos Estados Unidos desrespeitava tanto o direito internacional previsto pela OMC - cláusulas do TRIPS que permitiam a licença compulsória em casos de emergência, também presentes na legislação norte-americana quanto os princípios de autodeterminação e não-intervenção de ambos os povos introjetados na ação internacional do Brasil. Além disso, tratava-se de uma disputa entre Davi (Brasil) e Golias (EUA).

No plano doméstico, houve também amplo apoio à causa brasileira, começando pelo governo e parte da sua burocracia: o presidente da República e os ministros da Saúde, da Fazenda e das Relações Exteriores. Em seguida, parlamentares afiliados ao Partido da Social Democracia Brasileira (PSDB) e à aliança governista, a indústria farmacêutica nacional que produz genéricos, a população soropositiva (que geralmente se encontra organizada em ONGs, como o Grupo 
Multilateralismo, Democracia e Política Externa no Brasil...

Pela Vidda, Fundação Viva Cazuza, dentre outras que geralmente atuam como parceiras domésticas de ONGs globais), assim como também a opinião pública em geral (eleitor médio).

No tocante às diferentes esferas do governo, posso afirmar que cada qual teve seu interesse na questão, como veremos adiante. Contudo, evidências empíricas permitem-me sugerir que o Poder Executivo utilizou o mecanismo de licença compulsória na disputa das patentes, entre outros motivos, com fins eleitorais.

O ministro da Saúde, José Serra, era presidenciável, sendo confirmado, posteriormente, como candidato do PSDB. Durante sua campanha eleitoral, a alusão aos medicamentos genéricos esteve sempre presente. ${ }^{3}$ Paralelamente, Serra prometia também que, se eleito e se a indústria farmacêutica internacional não diminuísse os preços dos medicamentos, ele se empenharia em utilizar o mecanismo de licença compulsória presente na Lei de Patentes brasileira para fornecer tratamento de HIV/AIDS a um maior número de doentes. Para ele: "O governo tem que exercer o seu poder de pressão na questão das patentes" (SERRA..., 2003). O presidente da República Fernando Henrique Cardoso, durante o processo eleitoral, observou que, na gestão Serra no Ministério da Saúde, foi regulamentada a lei dos genéricos, os quais "[...] baratearam os preços dos medicamentos e possibilitaram a quebra de patentes. E não há patente que resista às dificuldades do povo" (DEFERÊNCIAS..., 2002).

O barateamento do tratamento para os doentes de HIV/AIDS seria benéfico também para o ministro da Fazenda, pois as despesas com o "coquetel" seriam reduzidas, tornando as verbas destinadas à saúde pública suficientes para tratar mais pacientes e de maneira mais eficaz. De modo geral, essa política teria impactos positivos na melhora das finanças públicas.

Apesar de tudo, o fator determinante da vitória brasileira está conectado à posição do MRE. A elaboração e a execução da estratégia ven- 
cedora em parceria com agências estatais envolvidas na questão, assim como parceiros internacionais e nacionais, sobretudo da sociedade civil, certamente foram uma experiência inédita levada a cabo pelo MRE. Esta desvendou e demonstrou o papel que a articulação entre as agências públicas e atores privados possui na formulação e implementação de aspectos da política exterior do país na era da globalização, o que serviu também para amenizar as críticas feitas à instituição de insulamento burocrático, ampliando sua credibilidade nacional junto à sociedade brasileira e internacional, na medida em que sua ação externa estava fundamentada em legitimidade democrática. Além disso, serviu como aprendizado de como utilizar as estruturas globais de poder em prol dos interesses brasileiros e auxiliar na construção de bens públicos globais, como a OMC, a serem utilizados por outros países menos favorecidos contra as práticas comerciais desleais, sobretudo, dos países desenvolvidos.

Enfim, quero destacar que, a partir da questão das patentes, José Serra conseguiu mobilizar a seu favor atores domésticos e internacionais, tais como a indústria farmacêutica nacional, os laboratórios nacionais, as organizações da sociedade civil no Brasil e no exterior que auxiliam doentes de AIDS, parte da população sensível ao tema da saúde, apoio parlamentar, de organizações internacionais, de parte da sociedade civil estadunidense, de vários países etc. Obviamente que com claras pretensões eleitorais.

Entretanto, além da elaboração de uma excelente política pública de saúde, reverenciada em todo o mundo, mais importante foi demonstrar a eficácia, a credibilidade e a legitimidade auferidas por estratégias de política externa que contemplem o apoio doméstico e internacional da ação do Estado brasileiro na OMC. Com resultado final bastante positivo, pois conduziu os negociadores dos Estados Unidos a optarem por retirar a queixa, recuando na sua posição intransigente de defesa de direitos de propriedade intelectual da indústria farma- 
Multilateralismo, Democracia e Política

Externa no Brasil...

cêutica norte-americana, e a negociar bilateralmente com o Brasil uma solução para o problema.

Como discutirei adiante nas considerações finais, esse contencioso das patentes serviu como modelo, como um ensaio bem-sucedido para a ampliação da participação dos atores domésticos brasileiros em questões internacionais em parceria com o governo brasileiro, aumentando o grau de democracia e, portanto, legitimidade e credibilidade da política externa brasileira vis-à-vis seus parceiros internacionais e na OMC.

A única objeção foi não ter contribuído com o Ministério das Relações Exteriores para a institucionalização do processo, relegando a experiência, que deveria tornar-se padrão para o benefício do país, a ações conjunturais, como buscarei demonstrar, mais adiante, quando analisar a "vitória" brasileira no contencioso dos subsídios agrícolas ao algodão norte-americanos.

\section{A Disputa dos Subsídíos Agrícolas na OMC: 0 Caso do Algodão}

O Brasil solicitou a instauração de um panel na OMC questionando a legalidade dos subsídios oferecidos aos produtores de algodão dos Estados Unidos e foi atendido em 18 de março de 2003. Além disso, a OMC atendeu ao pedido de reserva de direitos de outros países ${ }^{4}$ no processo de arbitragem.

De acordo com o MRE, atendendo à demanda de produtores brasileiros, a Lei Agrícola (Farm Bill) norte-americana distorce o mercado internacional de algodão, baixando os preços da commodity aproximadamente $15 \%$ e estimulando o "desvio de comércio". Dessa maneira, os produtores norte-americanos vendem o produto a preços menores, conquistando fatias expressivas do mercado que poderiam 
ter como beneficiários o Brasil e outros países, como Benin, Chade e Mali. As perdas brasileiras foram estimadas em US\$ 600 milhões somente em 2001 (OMC, 2002). No mercado internacional, os subsídios causaram queda de 12,6\% no preço do produto entre 1999 e 2002 (SOBRAL, 2004).

Para comprovar essa ilegalidade, o governo brasileiro apresentou aos juízes da OMC, auxiliados pelo setor privado e ONGs, inclusive de outros países, dados demonstrativos de que os Estados Unidos concederam aos seus produtores de algodão, em quatro anos, subsídios estimados em torno de US\$12,9 bilhões. Valor este muito além dos US\$ 8 bilhões permitidos conforme compromissos assumidos durante a Rodada Uruguai. Este fato, portanto, configuraria que os Estados Unidos haviam rompido com a "Cláusula de Paz" do Acordo Agrícola, devendo ser condenados. Diante dos argumentos, em 5 de setembro de 2003, o panel da OMC deliberou que a questão deveria ser averiguada.

Em 26 de abril de 2004, após várias consultas às partes, a OMC anunciou uma decisão preliminar favorável ao Brasil. A mesma foi confirmada em 18 de junho, afirmando a ilegalidade e a necessidade de redução dos subsídios norte-americanos aos produtores de algodão (LOBBY..., 2004; SOBRAL, 2004) por terem causado "sérios prejuízos" aos interesses brasileiros. Apesar de a decisão garantir apenas uma "vitória parcial", pois os Estados Unidos podem apelar da mesma, e de fato o farão (LEO; LANDIM, 2004), vale a pena, em um primeiro momento, indagar sobre os motivos de mais um "sucesso" e, depois, indicar possíveis cenários desse resultado.

Como veremos adiante, novamente, o sucesso relativo da empreitada brasileira na OMC está relacionado tanto com a escolha estratégica do multilateralismo como base da ação externa do país quanto com a capacidade de o governo articular as agências públicas coordenadas pelo MRE bem como parceiros internacionais e nacionais, sobretudo 
Multilateralismo, Democracia e Política Externa no Brasil...

da sociedade civil, para a formulação e implementação da política exterior do Brasil contemporâneo.

No caso específico do contencioso do algodão, a formulação da estratégia brasileira teve início na sociedade civil, especificamente a partir das reclamações dos produtores que se queixavam de que, quando começavam a ter lucros com a exportação, eram prejudicados pelos baixos preços das comoddities norte-americanas amplamente subsidiadas. Pedro de Camargo Neto, membro importante da Sociedade Ruralista Brasileira (SRB), resolveu dedicar-se à solução do problema. Seu sucesso foi tanto que Scott D. Andersen, o advogado que representa o Brasil no escritório em Genebra da Sidley Austin Brown \& Wood, classifica-o como "[...] o chefão, o visionário dos casos relativos ao algodão e ao açúcar" (LOBBY..., 2004).

Segundo Camargo Neto, sua empreitada não foi fácil. Ele enfrentou todo tipo de obstáculo político do governo brasileiro, principalmente do MRE. Em suas palavras,

"[...] alguns funcionários do Ministério das Relações Exteriores não desejavam enfrentar a superpotência mundial no terreno das questões agrícolas. Eu levei até eles um estudo sobre a contestação dos subsídios e eles disseram, 'Traga-me outro'. A seguir, eu levei dois e eles me pediram outros quatro. Certas pessoas fizeram de tudo para me atrapalhar" (LOBBY..., 2004).

No entanto, quando Camargo Neto foi convidado para fazer parte do governo, como vice-ministro da Agricultura na gestão FHC, não teve dúvidas: mobilizou o ministério e a sociedade civil em torno da questão. O primeiro passo foi acumular força política para a empreitada e coordenar as diferentes esferas do governo e do setor privado envolvidas com o contencioso a partir do Ministério da Agricultura que à época era ocupado por Marcus Vinícius Pratini de Moraes. Nesse sentido, Camargo obteve apoio da SRB, da Associação Brasileira dos Produtores de Algodão (Abrapa), dos maiores produtores do país, como Adilton Sachetti do Mato Grosso, enfim, do setor privado 
que financiou boa parte dos custos da disputa comercial. Somou-se a essa ampla coalizão a bancada ruralista no Congresso brasileiro e vários governadores e prefeitos de regiões produtivas de algodão, inclusive trabalhadores rurais e seus sindicatos.

O segundo passo foi convencer o restante do governo, principalmente o MRE, a levar a demanda doméstica para a OMC, o que significava enfrentar os Estados Unidos em uma arena em que a experiência demonstrava que eles prevaleciam. Além disso, estaria sendo rompido um bom padrão de relacionamento alcançado entre ambos os países durante os anos 1990, especificamente com a coincidência e empatia no governo de FHC no Brasil e de Clinton nos Estados Unidos. A diplomacia brasileira, como afirmou Camargo Neto, encontrava-se cética e reticente em iniciar o contencioso, em virtude da grande possibilidade de derrota e do impacto negativo que a ação teria sobre a boa relação entre os países, a qual poderia, muito provavelmente, afetar outros setores nos quais o Brasil estava conquistando vantagens econômicas.

Duas mudanças alteraram esse quadro. Primeiro, nos Estados Unidos, a troca de governo em janeiro de 2001, quando G. W. Bush, republicano, substituiu Bill Clinton, democrata. O novo governo alterou o modo de condução da política externa norte-americana. De preponderantemente multilateral, ela passou a ser majoritariamente unilateral. A agenda de segurança tendeu a prevalecer sobre a agenda comercial. Em síntese, a ausência de empatia entre os governos de FHC e G.W. Bush combinada à agenda desfavorável ao interesses brasileiros serviu para arrefecer a posição do MRE.

Paralelamente, no Brasil, o presidente Fernando Henrique Cardoso promoveu uma reforma ministerial pela qual Celso Lafer emergiu como ministro das Relações Exteriores. Em seu discurso de posse, Lafer afirmou que voltava ao Itamaraty para 
Multilateralismo, Democracia e Política Externa no Brasil...

“[...] traduzir criativamente necessidades internas em possibilidades externas. Esta tradução exige, numa democracia, mecanismos permanentes de consulta com a sociedade civil. Em minha gestão aprofundarei os canais de interação entre o Itamaraty e os diversos atores da vida nacional - Legislativo, os partidos políticos, a mídia, os estados que integram a federação, os sindicatos, os empresários e suas associações, as universidades e o mundo intelectual, as organizações não-governamentais" (LAFER, 2001).

Ou seja, Lafer assumiu o cargo declaradamente suscetível e disposto $a$ atender às sensibilidades e às demandas da sociedade civil brasileira. As diferenças entre o Ministério da Agricultura, na figura de $\mathrm{Ca}-$ margo Neto, e o MRE desaparecem. Instalou-se no governo uma ampla convergência que, com a cooperação do setor agrário, passou a formular a estratégia brasileira na OMC.

Nessa direção, foi dado o terceiro passo. O Ministério da Agricultura mapeou os principais estudos internacionais sobre subsídios norte-americanos em busca de argumentos para a demanda brasileira. Obteve auxílio nessa tarefa da Oxfam, que realizou um amplo estudo sobre subsídios ao algodão fornecido pelos Estados Unidos e seus efeitos nefastos sobre os pobres agricultores africanos; da Environmental Working Group, que reforçou o trabalho da Oxfam e demonstrou que o mesmo ocorre com outros produtos, tais como trigo, arroz, açúcar etc.; do Institute for Agriculture and Trade Policy, de Minneapolis, o qual apontou "[...] os desastrosos resultados da política agrícola dos EUA, que derruba preços das commodities e assegura as diferenças com subsídios" (EUA, 2004b); do International Cotton Advisory Committee (ICAC), que, apesar do ceticismo, apoiou a iniciativa brasileira; da Action Aid, que se dedica ao estudo do comércio internacional e repassou o dado de que mais de 9 milhões de pessoas da África Ocidental dependem da renda da cotonicultura; e, por fim, do auxílio providencial do economista norte-americano Daniel Sumner, professor e pesquisador da Universidade da Califórnia e ex-secretário assistente do Departamento de Agricultura dos Estados Unidos (United States Departament of Agriculture (USDA)). Ele 
adaptou um modelo econométrico utilizado pelo Congresso dos Estados Unidos para avaliar produção, preço e comércio afetados pela política agrícola norte-americana e organizou o relatório com os dados utilizados para dar credibilidade ao argumento e à demanda brasileira. Cabe ressaltar que a área agrícola é uma das únicas em que os países em desenvolvimento encontram amplo apoio interno liderado por organizações não-governamentais e mesmo parte das entidades de agricultores, nos países desenvolvidos, como vimos aqui.

Em seguida, o papel do Ministério das Relações Exteriores foi formular o argumento conforme a demanda do setor agrário brasileiro, adaptá-lo às premissas básicas da política externa do país e apresentá-lo para a OMC. Como também vimos, muitos países entraram como partes interessadas. Principalmente os países africanos, que, após o anúncio do resultado, comemoraram a "vitória brasileira". O secretário-geral do Ministério do Comércio do Chade, Atidiani Nourene, afirmou: "Essa decisão é fundamental para milhares de produtores africanos para quem a cultura do algodão é uma questão capital". Já o embaixador do Benin, Samuel Amehou, saldou o parecer da OMC constatando que: "Os países africanos são competitivos, mas os subsídios americanos sufocam nossos produtores. Isso pode começar a mudar a partir de agora" (VITÓRIA..., 2004). Enquanto isso, o setor agrário representado, principalmente pela SRB e pela Abrapa, em plena simbiose com o governo brasileiro, teve o papel de auxiliar financeiramente na elaboração da estratégia brasileira vitoriosa que, até o momento, custou US\$ 1 milhão. O montante foi arrecadado por meio de uma rifa organizada pelos produtores de algodão (ROSSI, 2004).

Outro fator importante para a "vitória" da estratégia brasileira foi o apoio obtido de organizações internacionais importantes, tais como a ONU via Programa das Nações Unidas para o Desenvolvimento (PNUD), o Banco Mundial, o Fundo Monetário Internacional (FMI), a Organização para Cooperação e Desenvolvimento Econômico 
Multilateralismo, Democracia e Política Externa no Brasil...

(OCDE) etc., as quais, freqüentemente, têm salientado que países em desenvolvimento como o Brasil e os africanos teriam mais condições de dar suporte à sua população, diminuindo a condição de pobreza, por meio do livre comércio dos bens agrícolas, no qual são competitivos, e não por meio de programas transitórios de ajuda financeira. Segundo essas organizações internacionais, o resultado do panel pode trazer benefícios nesse sentido.

Enfim, a parcial "vitória" brasileira no contencioso do algodão contra os Estados Unidos nos permite projetar três cenários diferentes para o desenvolvimento futuro das negociações em torno da liberalização do comércio internacional.

No primeiro deles, mais otimista, o triunfo brasileiro marcaria o início da flexibilização do protecionismo agrícola norte-americano e de outros países desenvolvidos. Seu significado simbólico foi demonstrar que os países ricos não podem "mais continuar ficando na negativa absoluta nas negociações agrícolas" (VITÓRIA..., 2004) em detrimento dos países em desenvolvimento. Na prática, essa "vitória" consolidaria jurisprudência na OMC em favor dos países em desenvolvimento (OMC..., 2004), podendo ser expandida para produtos semelhantes, como o arroz e o trigo (LEO; LANDIM, 2004).

Como resultado, os produtores de bens agrícolas nos países em desenvolvimento e Países de Menor Desenvolvimento Relativo (PMDRs) ganhariam maior competitividade internacional. Esta se traduziria em aumento das exportações, diminuição do desemprego e de suas conseqüências, entre outros prováveis benefícios, que permitiriam a países como Benin, Chade e Mali, que têm boa parte de sua economia dependente da exportação de algodão, recursos suficientes para o enfrentamento de graves problemas sociais.

O segundo cenário, pessimista, tem como hipótese uma apelação bem-sucedida dos Estados Unidos na OMC. Caso isso viesse a ocorrer, os produtores dos países desenvolvidos poderiam ganhar novo 
fôlego na defesa dos subsídios agrícolas, o que dissuadiria governos e produtores dos países em desenvolvimento e PMDRs a moverem esse tipo de processo na OMC, tendo em vista seus elevados custos políticos e financeiros. Manteria, segundo Rubens Ricupero (2004), o receio dos países em desenvolvimento em contestar os países desenvolvidos, deslegitimando o papel desempenhado pela OMC no sistema internacional.

De fato, o governo norte-americano já afirmou que vai apelar contra a decisão da OMC. Zoelick chegou a debochar do resultado ao afirmar que "Uma coisa é ganhar o caso, outra é conseguir os resultados desejados" (EUA..., 2004a). Alertou ainda que o contencioso do algodão pode prejudicar as negociações da ALCA, e que, se outras ações como essa forem movidas na OMC, a Rodada de Doha poderia ser debilitada, praticando de antemão um certo tipo de dissuasão (BUSH..., 2004).

O terceiro cenário, bem mais provável, é híbrido. Combina aspectos dos anteriores. Nem Brasil nem Estados Unidos saem completamente vitoriosos, mas, certamente, o processo de liberalização comercial global sai perdendo. Isso porque, por um lado, os Estados Unidos ao apelarem até a última instância na OMC buscam exclusivamente ganhar tempo. Para tanto, mudarão regras de seu programa de apoio aos produtores de algodão de forma a torná-lo mais compatível com as normas da OMC. Certamente, o Brasil novamente irá recorrer alegando a manutenção da incompatibilidade. O processo de arbitragem continuará e serão dados prazos maiores (que podem chegar a dois anos) para a solução do contencioso que podem chegar a dois anos.

Tais estratégias têm o nítido objetivo de alongar até 2007 o contencioso para obter apoio do setor agrícola à reeleição de Bush. Além disso, nesse ano vence a Farm Bill (Lei Agrícola dos EUA). Dessa maneira, os negociadores norte-americanos buscarão manter os subsídi- 
Multilateralismo, Democracia e Política Externa no Brasil...

os domésticos e o apoio político ao governo do setor agrícola e, simultaneamente, respeitar as regras da OMC. O resultado final é atrasar ainda mais a liberalização comercial agrícola. Realidade que interessa tanto à União Européia quanto ao Japão, que terão também mais tempo para dar início ao fim dos seus subsídios.

Por outro lado, o Brasil e os países do G-20 recusarão discutir novas ondas de liberalização comercial de setores que interessam aos países desenvolvidos, tais como serviços, compras governamentais, propriedade intelectual etc. Ao seu lado, contarão com o apoio moral da comunidade internacional e de atores importantes da sociedade civil global, o que gerará um completo impasse nas discussões sobre liberalização comercial global e nos acordos regionais, como ocorreu em Cancun, no bojo da Rodada de Doha, no final de 2003, que perdurará, pelo menos, a médio prazo. E tornou a ocorrer na VI Reunião Ministerial de Hong Kong no final de 2005. Todos sairão perdendo, principalmente, os países africanos, menos favorecidos; em seguida, os países em desenvolvimento, reunidos em torno do G-20; e, por fim, os países desenvolvidos.

O custo político internacional, sobretudo moral, será bastante elevado para os Estados Unidos e poderá gerar impactos na sua liderança benigna, assim como vem ocorrendo na área da segurança, principalmente no tocante ao Iraque e ao terrorismo transnacional. Ou os Estados Unidos retomam a construção de instituições e jurisprudência internacional, abandonando o unilateralismo característico da administração G. W. Bush, e aprofundam o movimento contínuo, benéfico ao Brasil, desde 1945, de ordenação de uma lógica cooperativa, cosmopolita, a partir do ideal kantiano nas Relações Internacionais. Ou dão início a uma nova era em que a lei da selva tende a prevalecer, o que seria dramático para a comunidade internacional, sobretudo para o Brasil, que, apostando no multilateralismo, pautou sua inser- 
ção internacional nos últimos anos a partir da lógica da "autonomia pela integração".

Em resumo, vale destacar que uma articulação virtuosa entre policy-makers e sociedade civil pode garantir tamanha legitimidade e credibilidade aos negociadores brasileiros na OMC, a ponto de o país ter uma participação ativa e decisiva na configuração de bens públicos globais essenciais para a defesa dos interesses da sociedade brasileira que afetam o cotidiano de cada cidadão bem como para a comunidade internacional. Nas Considerações Finais, aprofundarei essa questão.

\section{Rationale dos argumentos e agenda futura}

Observar e compreender a interação dos atores que contribuíram para o estabelecimento da estrutura de preferência doméstica durante o processo de formulação das estratégias e das posições a serem adotadas pela diplomacia brasileira nas negociações internacionais, sobretudo na OMC, no tocante ao contencioso das patentes e do algodão, é essencial para o futuro do país, por, pelo menos, dois motivos principais.

Primeiro, ambos os estudos de caso fornecem subsídios importantes para refletirmos sobre o desenho institucional mais adequado para o Estado brasileiro ter ampla capacidade de transformar as necessidades da sua sociedade civil em oportunidades internacionais. A rationale básica, para tanto, é traduzir seu legado histórico-diplomático em prol da ampliação da democracia e do multilateralismo no mundo em prática doméstica. Por meio da construção de instituições políticas democráticas eficazes na canalização das demandas dos grupos econômicos e sociais que têm interesses em jogo nas negociações comerciais internacionais contemporâneas. 
Multilateralismo, Democracia e Política Externa no Brasil...

Em outras palavras, as experiências de interação entre policy-makers e atores domésticos e internacionais acumuladas tanto pelo Estado brasileiro na figura da sua diplomacia quanto pela sociedade civil em ambos os contenciosos na OMC nos permitem afirmar ser necessário a elaboração de instituições democráticas ex-ante e ex-post para a formulação da política externa do Brasil, cabendo ao MRE a função de implementá-la. Certamente, um ponto de partida razoável é a experiência, a ser aperfeiçoada, da relação institucionalizada inaugurada durante o governo FHC, sobretudo no período de Celso Lafer como ministro das Relações Exteriores, entre a Coalizão Empresarial Brasileira (CEB) e o MRE, mas que, no governo Lula, vem perdendo paulatinamente sua expressão, que deveria ser imediatamente recuperada e aprofundada por meio de uma agenda futura de mudanças nessa questão.

\section{A Coalizão Empresarial Brasileira vem demonstrando}

“[...] sérias preocupações em relação ao andamento do diálogo entre o empresariado e o governo. Consideram que há falta de clareza dos objetivos e estratégias utilizadas nos processos negociadores, que a ambição é pouca nos acordos que estão sendo negociados e que há evidentes dificuldades na definição de uma estratégia Mercosul de negociação com parceiros extrabloco. Criticam, ainda, a assinatura de acordos antes da efetiva conclusão de negociações, a limitada participação da iniciativa privada na discussão das estratégias de negociação, o prazo exíguo para consultas e o difícil acesso às informações" (COMUNICAÇÃO..., 2004).

Roberto Teixeira da Costa corrobora com a idéia ao afirmar que "Sem um diálogo totalmente transparente entre setor público e privado, dificilmente haverá progresso nas negociações e não se conseguirá atingir objetivos que realmente atendam às necessidades do país". Ele reconhece que “(...) o papel dos negociadores não é fácil, pois sua capacidade de dialogar tem que ser mantida em duas frentes: a interna, na busca de um mínimo consenso, e a externa, obtendo os melhores termos para o nosso país. Mas defende a manutenção de um canal amplo nessas conversações" (LIMITES..., 2004). 
Muitas alternativas para o equacionamento dessa questão podem ser encontradas na experiência de outros países e podem servir como modelo para o Brasil construir suas instituições democráticas para o tratamento da política externa, especificamente, das negociações comerciais internacionais. O exemplo paradigmático é o Escritório do Representante de Comércio dos Estados Unidos (em inglês, United States Trade Representative (USTR)), em que as interações entre grupos de interesse, Legislativo e Executivo, são perceptíveis e dotadas de institucionalidade (VIGEVANI, 1995). Isso porque o USTR, agência do Executivo para o comércio internacional, possui a participação formal de representantes de empresas e associações privadas, além de legisladores, no seu processo de formulação de políticas (NOLAND, 1997; VIGEVANI, 1995). As ações do USTR são acompanhadas de perto, quando não delimitadas, pelo Legislativo, o que fica evidente ao se analisar a TPA de 2002 (EMBAIXADA DO BRASIL EM WASHINGTON, 2002). Como vimos, o Projeto de Lei 189/2003 ${ }^{5}$ do senador Eduardo Suplicy (Partido dos Trabalhadores (PT)/SP) visa criar instrumentos e mecanismos institucionais semelhantes e, provavelmente, talvez seja uma alternativa viável para o Brasil. Ou, pelo menos, pode dar início a uma agenda de ajustes no padrão de tomada de decisões sobre a política externa do país no contexto democrático.

No caso dos Estados Unidos, fica evidente que as relações domésticas entre grupos de interesse, parlamentares e membros do Executivo, equalizadas por estruturas e instituições domésticas, como o USTR e a TPA, funcionam como correias de transmissão dos interesses domésticos norte-americanos para a sociedade internacional. Tendo em conta o poder dos Estados Unidos e sua relevância para a formação dos regimes internacionais, o USTR tem grande capacidade de internacionalizar e legitimar as suas preferências domésticas no regime internacional de comércio, cristalizando-as, por exemplo, na OMC. Como observamos no contencioso do algodão, a diploma- 
Multilateralismo, Democracia e Política Externa no Brasil...

cia brasileira parece estar buscando resultado semelhante no tocante à liberalização do comércio agrícola a partir da OMC. Esse caso poderá vir a favorecer a competitividade agrícola brasileira e, mais importante, evitar que a jurisprudência internacional se consolide exclusivamente a partir da realidade dos países desenvolvidos. No estudo de caso das patentes, o recuo dos Estados Unidos permitiu a flexibilização do regime internacional de patentes - TRIPS - para atender às demandas e às necessidades dos países em desenvolvimento e dos PMDRs.

Em um segundo momento, o "sucesso relativo" do Brasil na OMC, em ambos os estudos de caso aqui analisados em, só foi possível em decorrência de três elementos principais: escolha do multilateralismo na OMC no bojo da "autonomia como integração" como estratégia de ação internacional; a busca por demandas de forte apelo moral; e, por fim, a interação democrática com atores domésticos e internacionais. A interconexão entre esses três elementos proporcionou credibilidade e legitimidade à estratégia de política externa brasileira durante as arbitragens nos panels e às negociações comerciais internacionais na $\mathrm{OMC}$.

\section{Considerações Finais}

Em suma, podemos afirmar que o contencioso das patentes permitiu ao Brasil e a muitos aliados flexibilizar o TRIPS em prol das suas necessidades. Além disso, serviu como pano de fundo para o estabelecimento de alianças e coalizões políticas sul-sul no governo Lula, especificamente o estabelecimento do Fórum de Diálogo Índia, Brasil e África do Sul (IBAS).

Enquanto o contencioso do algodão, mais abrangente, pode significar um novo elemento na configuração do regime de comércio internacional, o contencioso das patentes poderá ter impacto direto na configuração do ambiente internacional relacionado à questão dos 
subsídios agrícolas, sendo amplamente favorável à sociedade brasileira e a outros países em desenvolvimento e PMDRs. Serviu também como base de sustentação e unidade do G-20 durante a V Conferência de Cancun da OMC e da VI Conferência Ministerial da OMC em Hong Kong, ocorrida em dezembro de 2005, na qual houve uma fratura nas posições dos Estados Unidos e da União Européia.

Por fim, vale ressaltar que a credibilidade e a legitimidade da estratégia brasileira para tanto só foi possível por causa da interação democrática entre policy-makers e sociedade civil nacional e internacional em vários fóruns, sobretudo na OMC. Contudo, a falta de institucionalização pode relegar ambas as experiências à memória nacional. Portanto, torna-se imperativa a elaboração de uma agenda política a favor da institucionalização imediata desse padrão de relacionamento para o benefício do Brasil, que vinha se desenvolvendo no governo FHC sob a tutela de Celso Lafer, vis-à-vis as ações conjunturais que vêm sendo privilegiadas no governo Lula.

\section{Notas}

1. Atual PL-4291/2004.

2. Comunidades epistêmicas podem ser consideradas como "[...] canais por meio dos quais novas idéias circulam de sociedades a governos, bem como de país para país." (HAAS, 1992, p. 27) Ou, então, "[...] uma rede de profissionais com perícia reconhecida e competência em um domínio específico e com pretensão oficial de conhecimentos relevantes a políticas dentro daquele domínio ou área." (HAAS, 1992, p. 3, tradução minha).

3. O jornal Gazeta Mercantil, em 10/08/2002, publicou reportagem com o título "Grandes fotos do presidenciável José Serra, posando sorridente com remédios genéricos, começaram a surgir em farmácias do Rio".

4. Entre eles, Argentina, Austrália, Benin, Canadá, China, Comunidade Européia, Índia, Nova Zelândia, Paquistão, Paraguai, Taiwan e Venezuela. 
Multilateralismo, Democracia e Política

Externa no Brasil...

5. Atualmente, após a inserção de um substitutivo, o projeto está tramitando com um novo número: PL-4291/2004.

\section{Referências Bibliográficas}

ARAÚJO CASTRO, João Augusto de. Araújo Castro. Brasília: Editora UnB, 1982.

BUSH arma contra-ataque à vitória do Brasil. Folha de S. Paulo, São Paulo, 29 abr. 2004. Disponível em: <http://www1.folha.uol.com.br/fsp/dinheiro/ fi2904200436.htm>. Acesso em: 29 abr. 2004.

CARDOSO, Fernando Henrique. A arte da política: a história que vivi. Rio de Janeiro: Civilização Brasileira, 2006.

COMUNICAÇÃO truncada. O Estado de S. Paulo, São Paulo, 04 jul. 2004. <http://www.estadao.com.br/ecolunistas/sonia/04/07/sonia040705.htm>.

DEFERÊNCIAS a Serra. Jornal do Brasil, 07 fev. 2002.

EMBAIXADA DO BRASIL EM WASHINGTON. A lei comercial americana de 2002 e a "Trade Promotion Authority": o que é e como impacta as negociações comerciais. 2002. Mimeografado.

EUA insinuam que podem manter ajuda ao algodão. Valor Econômico, São Paulo, A-5, 15 jun. 2004.

EUA podem levar anos para reduzir subsídios condenados. Valor Econômico, São Paulo, A-5, 28 abr. 2004.

FONSECA JR., G. A legitimidade e outras questões internacionais. São Paulo: Paz e Terra, 1998.

HAAS, P. M. Introduction: epistemic communities and international policy coordination. International Organization, n. 46, p. 1-37, 1992.

LAFER, Celso. A OMC e a regulação do comércio internacional: uma visão brasileira. Porto Alegre: Livraria do Advogado, 1998. 
Brasil: dilemas e desafios da política externa. Revista do Instituto de Estudos Avançados da USP, n. 39, 2000.

A identidade internacional do Brasil e a política externa brasileira passado, presente e futuro. São Paulo: Perspectiva, 2001.

Mudam-se os tempos. Diplomacia Brasileira 2001-2002. Vols. I e II. Brasília: Funag/IPRI, 2002.

LEO, Sergio; LANDIM, Raquel. Decisão da OMC não encerra caso do algodão. Valor Econômico, São Paulo, p. A5, 15 jun. 2004.

LIMITES da OMC beneficiam países ricos. O Estado de S. Paulo, São Paulo, 3 mai. 2004. Disponível em: <http://www.mre.gov.br/portugues/noticiario/ nacional/selecao_detalhe.asp?ID_RESENHA=46621>. Acesso em: 12 mai. 2004.

LOBBY ruralista determinou vitória do Brasil na OMC. The New York Times, mar. 2004. Disponível em: <http://noticias.uol.com.br/midiaglobal/nytimes/ult574u3967.jhtm>. Acesso em: 04 mai. 2004.

NOLAND, Marcus. Chasing phantoms: the political economy of USTR. Washington: Institute for International Economics, 1997. Disponível em: $<$ http://www.iie.com/publications/wp/1997/97-1.htm>. Acesso em: 03 mai. 2004.

OLIVEIRA, Marcelo Fernandes. Breve ensaio sobre a política externa brasileira. Revista Autor, São Paulo, ano III, n. 24, jun. 2003.

OMC concorda que subsídios para algodão são um escândalo. Financial Times, 28 abr. 2004. Disponível em: <http://noticias.uol.com.br/midiaglobal/ fintimes/ult579u1109.jhtm>. Acesso em: 28 abr. 2004.

OMC - DS267. 2002. Disponível em: <http://www.wto.org/english/tratop_e/ dispu_e/dispu_subjects_index_e.htm\#bkmk33 >. Acesso em: 04 mai. 2004.

RICUPERO, Rubens. O prêmio da coragem. Folha de S. Paulo, São Paulo, 02 mai. 2004. Disponível em: <http://www1.folha.uol.com.br/fsp/dinheiro/ fi0205200403.htm>. Acesso em: 02 mai. 2004.

ROSSI, Clóvis. Rifa financia vitória do Brasil contra os EUA. Folha de S. Paulo, São Paulo, 28 abr. 2004. Disponível em: <http://www1.folha.uol.com.br/ fsp/dinheiro/fi2804200436.htm>. Acesso em: 28 abr. 2004. 
Multilateralismo, Democracia e Política

Externa no Brasil...

SERRA vai investir na quebra de patentes. Gazeta Mercantil, São Paulo, 10 ago. 2003.

SILVA, Carlos Eduardo Lins da. Política e comércio exterior. In: LAMOUNIER, Bolívar; FIGUEIREDO, Rubens. A era FHC: um balanço. São Paulo: Cultura, 2002.

SOARES de LIMA, Maria Regina. Instituições democráticas e política exterior. Contexto Internacional, Rio de Janeiro, v. 22, n. 2, jul./dez. 2000.

SOBRAL, Isabel. Brasil vence disputa do algodão contra os Estados Unidos. O Estado de S. Paulo, 19 jun. 2004. Disponível em: <http://www.mre.gov.br/ portugues/noticiario/nacional/selecao_detalhe.asp?ID_RESENHA=57545>. Acesso em: 19 jun. 2004.

VIGEVANI, Tullo. O contencioso Brasil X Estados Unidos da informática: uma análise sobre formulação da política exterior. São Paulo: Alfa-Omega/EdUSP, 1995.

; OLIVEIRA, M. F. Política externa no governo FHC: a busca de autonomia pela integração. Tempo Social, v. 15, n. 2, 2003.

VITÓRIA do país é comemorada pelos africanos. Folha de S. Paulo, São Paulo, 19 jun. 2004. Disponível em: <http://www1.folha.uol.com.br/fsp/dinheiro/ fi1906200436.htm>. Acesso em: 19 jun. 2004.

\section{Resumo}

\section{Multilateralismo, Democracia e Política Externa no Brasil: Contenciosos das Patentes e do Algodão na Organização Mundial do Comércio (OMC)}

O objetivo deste artigo é verificar se o aperfeiçoamento das instituições democráticas brasileiras no tocante ao processo de formulação da política externa por meio da elaboração e da ampliação de canais institucionais que facilitem a interação entre policy-makers e atores das organizações da sociedade civil pode melhorar o atendimento das demandas dos grupos de interesse, bem como ampliar a qualidade técnica da diplomacia brasileira du- 
rante as negociações comerciais internacionais. Combinada a opção estratégica pelo multilateralismo, verificaremos ainda se esse aperfeiçoamento pode gerar maior credibilidade e legitimidade internacional para as ações do Brasil na OMC, inclusive possibilitando ao país moldar regimes internacionais de comércio favoráveis aos seus interesses nacionais. Buscarei demonstrar a viabilidade do argumento analisando os contenciosos das patentes farmacêuticas e da questão dos subsídios agrícolas, especificamente o caso do algodão contra os Estados Unidos na OMC.

Palavras-chave: Multilateralismo - Democracia - Política Externa do Brasil - OMC

\section{Abstract}

\section{Multilateralism, Democracy and Foreign Policy in the Brazil: Disputes of the Patents and the Cotton in the WTO}

The objective of this article is to verify if the perfectioning of the brazilian democratic institutions in what refers to the foreign affairs making process through elaboration and ampliation of the institutional ways which can make easier the interaction between policy-makers and civil society organization's actors, can better the answer to demand from the technical quality of the brazilian diplomacy during the international commercial negotiations. Agreed the selection strategic at multilateralism, we will also verify if this perfectioning can create bigger international credibility and eligibility to the Brazilian actions at WTC, inclusively making possible to the country to mold international commerce regimes which favors to its national interests. We will search demonstrate the viability of the argument, analising the patents pharmaceuticals disputes and the agricultural subsidies questions, in specific, the cotton dispute in WTO with the United States.

Keywords: Multilateralism - Democracy - Foreign Affairs of Brazil WTO 